\title{
Multilingual Education: An Emerging Threat to Quality English Education in Eastern Ethiopia
}

\author{
Sanjay Kumar Jha \\ Department of English, Haramaya University, Ethiopia
}

\begin{abstract}
In 1994, Ethiopian constitutions underwent an amendment in which each regional state was given a right to choose, use, and diffuse its language from both cultural and educational perspectives. This amendment marked the welcoming sign of multilingual education in Ethiopia, but the current pattern of multilingual education has caused more harm than good to the end users (students) in terms of learning and mastering English language to an optimal level. The paper hypothesizes that multilingual education is one of the determinants for impairing the quality of English education in Eastern Ethiopia. So this research took the shape of an ethnographic perception-study not only to explore the adverse impacts of multilingual education on the quality of English education but also to seek mass views on reversing the current trend of multilingual (trilingual) education from (Mother Tongue + Amharic + English) to (English + Amharic + Mother Tongue) as a remedy. In this pursuit, 150 participants comprising 50 students, 50 teachers, and 50 government employees were selected using convenience sampling. The data were collected through unstructured interview and participant observation; whereas, the analysis of the data was made through analytic induction and percentile. As a part of findings, the paper presents six adverse impacts of multilingual education on English Education; and the participants' varied degree of consent on reversing the current pattern of trilingual education. The paper finally forwards apposite recommendations to streamline English in mainstream education to enhance the quality of English education.
\end{abstract}

Index Terms - multilingual/trilingual education, ELT (English Language Teaching), reverse

\section{INTRODUCTION}

Needless to say that English has not only become a lingua franca for us globally, but more importantly it has become a language of progress or a key to success in every walk of life (Jha, 2013). By contrast, English is being used paradoxically as a foreign language rather than second language in Ethiopian context because average Ethiopians believe that English can never be a crutch to survive in Ethiopian society (ibid). Therefore, English is foreign to most, and is known and used only by a small minority of educated, economic, and/or political elite in Ethiopia (Bogale, 2009). Although Ethiopia's need for English language is more intensified as globalization is the agenda of the time, the 'depressing picture of English language teaching' never improved (Eshetie, 2010).

In 1994, a constitutional amendment was made in which regional languages were permitted to be used as the medium of instruction in Ethiopia (Seidel, 2009). As a result, almost all the states showed their affinity towards mother tongue education which resulted into a trilingual education consisting of mother tongue + Amharic + English (Bogale, 2009). This amendment marked the welcoming sign of multilingual education in Ethiopia, but the proliferation of mother-tongue education has caused more harm than good to the end users (students) because mother tongues took the driver's seat and English went on the backseat. Such a proclivity of mother tongues in education has deprived the learners of learning and mastering English to an optimal level (Jha, 2013). There is a grave concern among the EFL learners especially in the Eastern Ethiopia that they have been learning English for several years but they are not able to master it (ibid).

Though many linguistic and non-linguistic factors (e.g., flaws in syllabus design, curriculum, language policy, test validity, communicative and pedagogic competence of the teachers, class and classroom size, etc.) can be attributed to the poor quality of ELT in Eastern Ethiopia, the present study hypothesizes multilingual education (Mother Tongue + Amharic + English) detrimental to the degrading state of English in general and poor performance of the learners in particular. Hence, this study aims at disseminating a new realm of discussion on how multilingual education in the form of trilingual education, i.e. (Mother Tongue + Amharic + English) has been emerging as a potential threat or worry to the Quality of English Education in Eastern Ethiopia.

Viewing the growing demands of English worldwide, almost all the multilingual countries confront a common question: Should the medium of instruction be a regional language, or national language, or international language (English)? Ethiopia being a multilingual country - with at least 70 regional languages and several dialects according to Wagaw (1999) - has been confronting the same question. Ethno-linguistic conflict is a persistent problem in Africa and Ethiopia is no exception. The current language policy, which is a potential source of conflict in Ethiopia, has caused a furore among Ethiopian academicians and social science researchers over language use and language policy.

It is apt to quote here two contradictory research papers titled Choosing a Working Language in Multiethnic Nations: Rethinking Ethiopia's Working Language Policy by Fiseha Haftetsion Gebresilassie and What Language Should Ethiopians Speak? by Ghelawdewos Araia (2012). In my view, both of them are right on their stance with their 
elucidation of the facts. On the one hand, Fiseha's paper discards Amharic and suggests adopting English as the sole official working language of the Federal Government with a slight difference of implementation in the area of education in the federal territories. Fiseha argues that the current language policy can harm Ethiopia by slowing down its global economic integration and fuel future conflicts that arise from disputes over language use. On the other hand, Araia (2012) strongly opposes Fiseha's proposal of discarding Amharic as working language and replacing it by English. According to Araia, Ethiopian officials, at this juncture, should not be tempted to accepting English in lieu of Amharic as a lingua franca of Ethiopia, for it would flagrantly contravene the Ethiopian interest and emasculate Ethiopian culture and identity.

\section{FoCUS AND SIGNIFICANCE OF THE STUDY}

Under the purview of the aforementioned pair of conflicting views, the concern of this paper is slightly different in that it suggests introducing English rather than regional language(s) as a medium of instruction right from nursery (elementary) grade to higher level education. The study is mainly focused on disseminating the astonishing ongoing change in the perceptions of the ELT practitioners, students, and the intellectuals of the region as shown in Fig. 3 below. The study is also significant in that there is a little research work on the current issue by the local researchers. So this study will serve as an eye-opener not only for the ELT practitioners but more importantly for the language policy makers to give a second thought on whether to retain the existing pattern of multilingual education, i.e. (Mother Tongue + Amharic + English) or to reverse the order as (English + Amharic + Mother Tongue) in the interest of the holistic growth of Ethiopia and the Ethiopians.

\section{QUESTIONS OF THE STUDY}

1) What are the major adverse impacts of multilingual education on the quality of English education?

2) What is the degree of consent on reversing the current trend of multilingual/trilingual education?

\section{Methodology}

For this study, a mixed design (qualitative and quantitative) has been used as the first research question required gathering qualitative data; whereas the second research question required gathering quantitative data.

\section{A. Participants}

The total population of the participants was 150 comprising 50 ELT practitioners at both university and school levels, 50 university students of different linguistic background, and 50 employees from government organisations: Dire Dawa Immigration Office, Harar Electricity Board, and three Commercial Banks of Ethiopia. The sites of the study were Harar, Dire Dawa, and Ziziga zones. The participants were selected using convenience sampling technique. This technique builds a sample on the basis of finding convenient or available participants. Though, this technique lacks representativeness and generalization, it helped to observe and interview those who were close at hand.

\section{B. Data Collection Method}

Viewing the sensitivity of the topic, only two data gathering instruments: participant observation and unstructured interview could be employed to elicit the required data. Participant observation enables researchers to assess what their subjects actually do, rather than what they say they do (Bloor \& Wood, 2006). Thus, the researcher used participant observation for gathering data as a part of answering the first research question by getting directly immersed with the participants in 8 EFL classrooms to assess progression of learning and mastering English along with proficiency level of the learners at university and secondary school level. In addition, the working staff of three nationalized banks and two government organizations: Dire Dawa Immigration office and Harar electricity board were also observed to know their levels of comprehension and expression in English. Unstructured interview was used to respond to the second research question because it allows the respondents to answer freely and the researcher to probe and explore the exact and related problem(s) as they crop up during the interview.

\section{Data Analysis}

The qualitative data gathered through participant observation were analyzed through analytic induction as it is a way to develop effects of a phenomenon to accurately present the reality of the situation being studied. Firstly, all the qualitative data were thematically categorized and interpreted in descending order of prominence, emphasis, and relativity of the adverse impacts of current trilingual education on the quality of English education. Secondly, the data gathered through unstructured interview were analyzed using percentile scale (see doughnut chart (Fig. 3) which shows the degree of consent on reversing the current trend of trilingual education.

\section{FINDINGS AND DISCUSSION}


This section has been divided into two parts. First, it discusses the major adverse impacts of trilingual education on the quality of English education. Second, it presents the degree of consent on reversing the current trend of trilingual education.

\section{Major Adverse Impacts of Trilingual Education}

Here, it is imperative to give brief accounts of six major adverse impacts of trilingual education which were found as a result of participant observation.

\section{A. English Is Learnt; Not Mastered}

Viewing the raised concern of the EFL learners that they have been learning English for several years but they are not able to master it, it is imperative to clarify the dichotomy between learning and mastering. Learning is understanding the linguistic components of a language and mastering is the part of using them in a well structured way with perfection and ease (Jha, 2013). If learning is process, mastering is product; if learning is path, mastering is destination (ibid). Mastering is aimed at acquiring utmost perfection in speech fluency, writing accuracy, stylistic nuances, word choice, accent, etc. Despite acquiring linguistic competence, the learners find it difficult to make their competence functional in real life situation for lack of mastering the language as illustrated in Fig. 1.

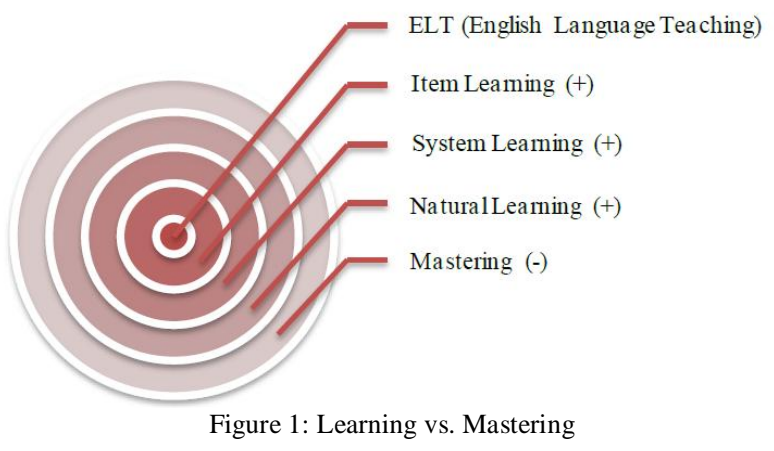

Fig. 1 shows the diminishing diffusion of learning and mastering English denoted through fading colour of the respective orbits. ELT is in the core; the first orbit shows item learning that is learning a language at word level; the second orbit is of system learning that is learning a language at sentence level. The third orbit shows natural learning in which learner starts learning a language either inductively or deductively. Here it is noteworthy that item learning, system learning, and natural learning have been given positive value (+) which indicates that these levels of learning take place in Ethiopian classrooms; whereas, the fourth orbit of mastering phase shows (-) value which implies that mastering does not take place in the Ethiopian classrooms (Jha, 2013). By the time mastering phase begins, the course duration comes to an end (ibid).

\section{B. Communicative and Pedagogic Incompetence of the Teachers}

Here, communicative incompetence implies teachers' low proficiency in using the language. Average teachers lack particularly in areas like word stress, intonation, sentence formation, words choice, stylistic, and cultural nuances of English language (Jha, 2013). Moreover, the majority of teachers lack the essential pedagogic (subject matter) competence to teach the learners of all levels. Many postgraduate students with poor proficiency in English are often assigned to teach undergraduate English courses. Such a practice of teaching by novice instructors may form a chain of incompetent teachers in Ethiopia (ibid).

\section{English: Taught as a Subject Rather Than a Language}

In present scenario, English is used merely as a subject for few months in schools and colleges (Jha, 2013). In a short duration of the course loaded with a number of formative and summative assessments, the learners' only concern is to pass English paper somehow rather than learning or mastering English language innately (ibid).

\section{English: A Medium of Obstruction Rather Than Instruction}

English is ignored as a medium of instruction from grade1 to 8. Normally, English becomes medium of instruction from grade 9 onwards (Jha, 2013). English is ignored again in diploma program especially in Oromia region. Students of this region complain of being dismissed from the university because of their incompetence in English. The students can express their subject-matter knowledge in L1 (mother tongue) but not in English (ibid). Not to say of active participation in classroom activities, students are often deprived of understanding what they hear from their teachers or read in their textbooks (Bogale, 2009). Moreover, study materials are not easily available in English. Thus, English proves more as a medium of obstruction rather than instruction (Stoddart, 1986).

\section{E. Confinement of English within Four Walls of Classroom}

There is hardly any opportunity of using English outside classroom. In the pursuit of establishing exclusive ethno-linguistic identity after the decentralization policy of mother tongue education introduced in 1994, the importance 
of English was undermined which caused utter lack of English exposure outside classroom. During unstructured interview, a striking fact came to be known that average Ethiopians hold the belief that they can easily do away with English as English is not a crutch to survive in Ethiopian society. This kind of mindset has confined English only within the four walls of classroom.

\section{F. Communication Chaos at Workplace}

In recent years, Ethiopia has witnessed a huge influx of expatriate staff in many job sectors. To meet the communicative needs of the expatriates, the Ethiopian workforce are not well-equipped with communicative competence in English at work place. It was found that only 5 to $10 \%$ of the staff is considerably proficient in terms of comprehending and expressing English with the expatriate clients.

2. The Degree of Consent on Reversing the Present Trend of Trilingual Education

To meet the answer of the second research question, the participants of the study were involved only in unstructured interview as they expressed their unwillingness to respond through other instruments of data collection. The reason of their unwillingness was to avoid any untoward entanglement due to political and tribal tinge involved in the issue. The following Fig. 2 is the rendition of transition from current pattern of trilingual education to the proposed pattern of trilingual education.

\begin{tabular}{|c|c|c|c|}
\hline $\begin{array}{l}\text { CURRENT } \\
\text { PATTERN }\end{array}$ & $\begin{array}{l}\text { Regional Language } \\
\text { (Gamo, Dawrona, etc.) }\end{array}$ & $\begin{array}{c}\text { National Language } \\
\text { (Amharic) }\end{array}$ & $\begin{array}{c}\text { International Language } \\
\text { (English) }\end{array}$ \\
\hline \multicolumn{4}{|c|}{$\downarrow$} \\
\hline $\begin{array}{l}\text { PROPOSED } \\
\text { PATTERN }\end{array}$ & $\begin{array}{c}\text { International Language } \\
\text { (English) }\end{array}$ & $\begin{array}{l}\text { National Language } \\
\text { (Amharic/Orominga) }\end{array}$ & $\begin{array}{l}\text { Regional Language } \\
\text { (Gamo, Dawrona, etc.) }\end{array}$ \\
\hline
\end{tabular}

Figure 2: Proposed pattern of reversing the current trilingual education

Fig. 2 shows that regional language is at the first place as a medium of instruction in the current pattern of trilingual education; whereas, the proposed pattern suggests to shift it to the third place in terms of priority and bring in English (international language of wider communication) from the third place to the first place as a medium of instruction from nursery grade to higher education. As far as the place of Amharic as a national language is concerned, it has been retained at its place without any shuffling. Along with the national language Amharic, I have put Orominga for the reason that more than half of the participants were not ready to view Amharic as a national language. They contend that Orominga has larger number of speakers than those of Amharic. Some 33 percent of Ethiopians speak Amharic as their mother tongue and nearly 80 percent or more of the total population speak and use Amharic either as a first or second language; whereas, 40 to 50 percent speak a variant of Orominga without having its own alphabet (Wagaw, 1999). Comparatively, Amharic has an edge over Orominga not only because of its long literary tradition but more because of its geographical location in central Ethiopia which serves as a bridge between northern and southern Ethiopia. Thus the need is to broaden one's view towards Amharic and see it as a language or tool of communication and not as a tool of oppression (Araia, 2012). Notwithstanding, the debate on the language use remains open from sociolinguistic perspective.

As for the degree of consent on reversing the order of current pattern of multilingual (trilingual) education, Fig. 3 shows $78 \%$ of the participants gave astonishing consent 'yes' on reversing the current trend of trilingual education; whereas $16 \%$ of the participants said 'no' on reversing the current trend of trilingual education and $6 \%$ of the participants preferred to abstain from making any remark on this issue.

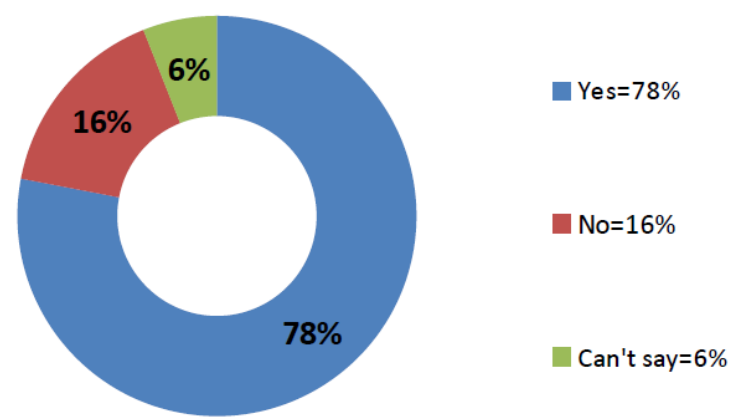

Figure 3: The degree of consent on reversing the order of trilingual education from MT+NL+IL to IL+NL+MT

N.B. Abbreviations: (MT=Mother Tongue, $\mathrm{NL}=$ National Language, IL=International Language.)

With respect to the results on exploring the degree of consent on reversing the trilingual education in Fig.3, it is imperative to mention here that almost all the participants agreed to this point that the necessity of reversing the current 
pattern of trilingual education is indeed a virtual reality but they expressed three variants of 'yes' or three differing degrees of 'yes' to the proposed pattern as follows.

TABLE 1:

THREE VARIANTS OF 'YES'

\begin{tabular}{|l|l|l|}
\hline Weak/Suppressed YES & Conditional YES & Strong YES \\
\hline $23 \%$ & $35 \%$ & $42 \%$ \\
\hline
\end{tabular}

Of the total participants who said 'yes', 23\% participants gave a 'weak yes'. The connotation of 'weak yes' implies to the unenthusiastic reply of the informants who said half-hearted 'yes' in a sluggish manner. $35 \%$ participants gave 'conditional yes'. Under 'conditional yes', all the participants put a condition that English should become the medium of instruction provided that it is introduced right from nursery grade or play school rather than grade one. Their assumptions were well-justified in that a child should start learning a language as medium of instruction from the age of 2 or 3 (critical phase) and reach at least intermediate fluency by the age of six or seven- the age when children start their formal education from grade one. This fact is well-grounded and well-supported too in several hypotheses of second language acquisition such as those of Krashen \& Terrell (1983), Steinberg (2001), and many others. It is noteworthy that $42 \%$ participants gave 'strong yes' as they were highly enthusiastic to reverse the current trend of trilingual education.

\section{CONCLUSION}

In its endeavor to answer two research questions, the paper has firstly presented six major adverse impacts of trilingual education which demand serious attention of the ELT practitioners and the language policy makers of the country to look into the same and overcome them at the earliest. Secondly, the paper presents the degree of consent on reversing the current trend of trilingual education from (MT+NL+IL) to (IL+NL+MT) as a remedial step to pave the path of quality English education. It has been noticed that by the time English is introduced as the medium of instruction from grade $8^{\text {th }}$ or $9^{\text {th }}$, the learners develop a sloppy competence in both spoken and written English. Late introduction of English is also a chief cause of mother tongue influence (MTI) on the learners' English. Moreover, the early introduction of English is crucial as one's memory and motor skills, i.e. 'the agility of speech organs to produce speech sounds of any second language diminish along with age (Steinberg, 2001).

It is apt to mention here that a country like India is already following the proposed pattern, i.e. English as the medium of instruction from nursery to higher education followed by national and state language. Perhaps, this trend can be attributed to Indians' academic and economic growth in global scenario. Though, some of the Ethiopian schools in Addis Ababa and neighboring areas have also introduced English from elementary Grade, but the average Ethiopians in Eastern zone are not ready to see any immediate change over language use. Hence, a solemn and sincere appeal is being made to the language policy makers of the country to make a need assessment survey to know whether the indigenous people want the proposed language as a medium of instruction or not. For instance, the absence of conscious language planning in case of introducing a blended language called Wogagoda (from Wolayta, Gamo, Gofa and Dawro) into the primary school education resulted in burning of textbooks worth 40 million birr, death of seven people, transfer of hundreds of teachers, and chaos that resulted in the demolition of infrastructures and even hotels (Daniel, 2001). The implementation of a multilingual policy without careful planning would result in a disaster as seen in the case of the introduction of the Wogagoda (Getachew \& Derib, 2006). In this scenario, English seems to play a role of catalyst not only from ethno-linguistic but also socio-economic perspectives provided English is introduced as a medium of instruction right from nursery to higher education. Moreover, the Ethiopians need to treat English as their second language rather than foreign language in every sphere of life. In the light of the results of the consent on reversing the order of the current trilingual education, the paper finally concludes that replacing mother tongue by English (as a medium of instruction) will dramatically enhance the quality of English education in the eastern Ethiopia and harvest holistic growth of the country and its citizens.

\section{RECOMMENDATION}

The paper forwards eleven apposite recommendations to pave the path of quality English education as follows.

A. No language should be imposed as a medium of instruction without proper need assessment of the indigenous people.

B. Let's view language as a medium of communication rather than a medium of social integration or disintegration.

A language of wider communication should be given due respect in terms of its usage.

C. English should be viewed more as a language rather than as a subject. In this regard, emphasis on class-test should be minimized and emphasis on real communication (both written and spoken) should be maximized.

D. To measure the pace and outcome of learning and mastering, competence-based test should be replaced by continuous performance-based tests involving analytical and interactive exercises (Jha, 2013).

E. Viewing the dismal state of English in Eastern Ethiopia, the language policy makers of the country need to give a second thought on prioritizing English. As a part of remedy, the current pattern of trilingual Education, which 
comprises 'mother tongue+Amharic+English', ought to be reversed, as 'English+Amharic+mother tongue' (Jha, 2013). The prime objective of reversing the present trend is to replace mother tongue by English so that English could become the medium of instruction right from nursery to higher education rather than grade $8^{\text {th }}$ or $9^{\text {th }}$ onwards.

F. In line with the above recommendation, Amharic and mother tongues should be taught as two compulsory papers in order to observe national \& ethnic harmony and to preserve linguistic heritage of the country.

G. Inculcate the sense of communicative professionalism in the staff at workplace to avoid communication chaos.

$\mathrm{H}$. The concerned teachers should have adequacy in terms of communicative and pedagogic competence before they undertake the task of ELT. A teacher without professional certification in Applied Linguistics, TEFL, TESOL, or ELT should not be assigned to teach English language (Jha, 2013). All the university departments of English need to conduct biannual TESOL international workshops for the existing and would-be English teachers in order to be informed of the latest happenings and developments in the field.

I. Do not confine English within the four walls of classroom. More learners are exposed to comprehensible inputs more they will master the language. Jha (2013) suggests some of the following comprehensible inputs which are really useful and globally-tested for all levels of learners to master the language.

- Watching TV cartoon programs like Barney, Mickey Mouse Club House, Sesame Street, etc. as they are not only fun-packed but highly educational to learn English in visual forms,

- Watching English movies, TV serials, Talk Shows like "Larry King Live” on CNN, "Hard Talk" on BBC, documentary channels like Discovery, National Geographic, The History, etc.,

- Listening radio programs like BBC, Voice of America, podcasts, etc.,

- Reading English story books, newspapers, magazines, etc.,

- Talking to or chatting with natives on social media.

J. To prioritize English, the Ethiopians need to use English as a second language rather than foreign language.

K. Since real quality education is transmitted to child right in the womb of the mother according to eugenics, women should be given the first priority of English education as educated mothers can most effectively diffuse the knowledge to their offspring (Jha, 2013).

In the light of the above discussion, it is imperative to say that the time is ripe for the Ethiopians to reverse the current trend of trilingual education and embrace English wholeheartedly as their second language in order to pave the path of socio-economic growth of the country and its citizens.

\section{ACKNOWLEDGMENT}

The author extends his sincere thanks to all the esteemed Ethiopian colleagues and the students of Haramaya University, Dire Dawa University, and Ziziga University for their cooperation in making honest remarks and giving insightful feedback during unstructured interview.

\section{REFERENCES}

[1] Araia, G. (2012). What Language Should Ethiopian Speak?. Ethiopia: Institute of Development \& Education for Africa (IDEA), Inc.

[2] Bloor, M., \& Wood, F. (2006). Keywords in Qualitative Methods. London: Sage Publications.

[3] Bogale, B. (2009). Language Determination in Ethiopia: What Medium of Instruction? Proceedings Paper: 16th International Conference of Ethiopian Studies, Trondheim 2-7 July 2007.

[4] Daniel, A. (2001). Language (Wogagoda) Caused Conflict in North Omo Zone: A Lesson towards Future Policy Implementations. Imperial Hotel Addis Ababa: Annual Workshop of OSSREA 8-9 June 2001.

[5] Eshetie, A. (2010). Language Policies and the Role of English in Ethiopia. Retrieved on Nov. 29, 2012, from http://www.besig.org/Libraries/Bielefeld_Docs/Roles_of_English_and_language_policies_in_Ethiopia.sflb.ashx.

[6] Fiseha, H. G. (0000). Choosing a Working Language in Multiethnic Nations: Rethinking Ethiopia's Working Language Policy. Unpublished master thesis.

[7] Getachew, A., \& Derib, A. (2006). Language Policy in Ethiopia: History and Current Trends. Ethiopia: Ethiopian Journal of Education and Science. www.ethiopiaed.net/images/257055575.doc. 37-62.

[8] Jha. S. K. (2013). English in Eastern Ethiopia is Learnt; Not Mastered. English Language Teaching, http://dx.doi.org/10.5539/elt.v6n4p42, 42-55.

[9] Krashen, S., \& Terrel, D. (1983). The Natural Approach: language acquisition in the classroom. New York. Pergamon Press.

[10] Seidel, K. (2009). Changes in Ethiopia's Language and Education Policy -Pioneering Reforms? Proceedings Paper: 16th International Conference of Ethiopian Studies, Trondheim 2-7 July 2007.

[11] Steinberg, D. (2001). Psycholinguistics: Language, Mind and World. London. Longman.

[12] Stoddart, J. (1986). "The Use and Study of English in Ethiopian Schools". Addis Ababa.

[13] Wagaw, T. G. (1999). Conflict of Ethnic Identity and Language of Education Policy in Contemporary Ethiopia. North East African Studies, Vol-6, No-3, 75-88. 




Sanjay Kumar Jha, born on $25^{\text {th }}$ December, 1972 in India, completed his MA in Linguistics at the University of Mumbai in 1998 as a university topper with first rank. Thereafter, he joined India's premier Indian Institute of Technology, Bombay as a Research Scientist to process machine translation and Wordnet projects of United Nations University, Tokyo and Ministry of Information Technology, Govt. of India respectively. In 2001, he joined Deccan College, Pune popularly known as 'Mecca of Linguistics' where he completed his $\mathrm{PhD}$ in linguistics in 2004. In 2001, he was also a visiting student at the University of California, Santa Barbara, USA for the Summer Program in Linguistics. He also holds five additional master degrees: MBA (Media Management), MA (Journalism and Mass Communication), PGDip (Human Rights), MPhil (Human Rights), and MEd (Education).

In his 15 years of job endeavors, he has taught Linguistics and English language in several leading institutions in India, Libya, and Ethiopia. Currently, he has been serving Haramaya University, Ethiopia as an Associate Professor of Linguistics-TEFL. His research interests include Second Language Acquisition, Innovation in ELT Methods, Machine Translation, Lexicography, and Contrastive Linguistics.

Dr. Sanjay has been the member of Linguistic Society of India, Linguistic Society of America, British Council, New Delhi, and American Center, New Delhi. As a linguist, he knows ten Indian and five foreign languages. Moreover, he is an internationally acclaimed columnist for several newspapers in English, Hindi, and Arabic worldwide. 